Artikel Penelitian

\title{
Sintesis Pigmen Geothit (a-FeOOH) dari Limbah Industri Kerajinan Besi dengan Metode Presipitasi
}

\author{
Choirun Nisa, Nur Aini, Lilik Miftahul Khoiroh*
}

Jurusan Kimia, Fakultas Sains dan Teknologi, Universitas Islam Maulana Malik Ibrahim Malang, Indonesia, 65144

INFO ARTIKEL

\section{Riwayat Artikel}

Diterima 8 Juni 2019

Direvisi 15 September 2019

Tersedia online 4 Desember 2019

*Email penulis korespondensi: lilikmfx@gmail.com

\section{ABSTRAK}

Iron handicraft is one of industries that process iron ore into handicraft products and produce lathe waste. Iron lathe contains $96.08 \%$ iron metal which is potential source as a precursor for synthesis of goethite pigment. The method used for synthesis was precipitation using $\mathrm{NaHCO}_{3}$ as precipitator agent. Synthesis was conducted at $70^{\circ} \mathrm{C}$ with variations of stirring speed such as 550,650, 750 and $850 \mathrm{rpm}$. The products were characterized by color reader, ultraviolet-visible (UV-Vis) spectroscopy, XRD and SEM-EDX. The data from color reader showed that the highest yellowness degree and lightness obtained at a stirring speed 550 rpm were 24.1 and 42.1, respectively. UV-Vis data showed that the maximum wavelength of goethite pigment was 600-624 nm. Based on XRD data, synthesized pigment was in goethite phase $(\mathrm{a}-\mathrm{FeOOH})$ for all samples with crystallite size $63.24 \mathrm{~nm}$ and the highest crystallinity was achieved at $550 \mathrm{rpm}$. SEM-EDX data showed that morphology pigment (a-FeOOH) was not uniform, there were impurities such as $\mathrm{Na}$ and $\mathrm{C}$.

Keywords: Lathe waste, precipitation, goethite, pigment

Industri kerajinan besi merupakan salah satu industri yang mengolah bijih besi menjadi produk kerajinan dan menghasilkan limbah bubut besi. Limbah bubut besi mengandung unsur besi sebesar $96,08 \%$ yang berpotensi sebagai bahan baku (prekursor) untuk sintesis pigmen geothit. Metode yang digunakan adalah metode presipitasi dengan agen pengendap $\mathrm{NaHCO}_{3}$. Sintesis dilakukan pada suhu $70^{\circ} \mathrm{C}$ dengan variasi kecepatan pengadukan 550 , 650, 750 dan $850 \mathrm{rpm}$. Produk hasil sintesis dikarakterisasi dengan color reader, spektroskopi ultraviolet-tampak (UV-Vis), XRD, dan SEM-EDX. Data color reader menunjukkan bahwa derajat kekuningan dan derajat kecerahan tertinggi didapatkan pada kecepatan pengadukan $550 \mathrm{rpm}$ yaitu berturut-turut 24,1 dan 42,1. Data UV-Vis menunjukkan panjang gelombang maksimum pigmen geothit hasil sintesis adalah 600-624 $\mathrm{nm}$. Hasil karakterisasi XRD menunjukkan bahwa pigmen hasil sintesis pada semua kecepatan pengadukan berfasa geothit $(\alpha-\mathrm{FeOOH})$ dengan derajat kristalinitas tertinggi pada kecepatan pengadukan 550 rpm dengan ukuran kristal 63,24 nm. Hasil SEM-EDX pada kecepatan $550 \mathrm{rpm}$ menunjukkan bahwa morfologi pigmen (a-FeOOH) hasil sintesis tidak seragam dan ditemukan adanya pengotor berupa unsur $\mathrm{Na}$ dan $\mathrm{C}$.

Kata kunci: Limbah bubut besi, presipitasi, geothit, pigmen 


\section{Pendahuluan}

Limbah bubut besi merupakan salah satu limbah yang banyak mencemari lingkungan. Berdasarkan Peraturan Pemerintah No. 85 tahun 1999, limbah bubut besi ditetapkan sebagai limbah bahan beracun dan berbahaya (B3). Limbah bubut besi terindikasi mengandung sejumlah logam berat yang dapat menimbulkan dampak negatif bagi kesehatan dan lingkungan. Limbah bubut besi mengandung besi cukup tinggi sehingga dapat berpotensi untuk digunakan sebagai bahan baku pembuatan besi oksida [1].

Besi oksida memiliki beragam aplikasi diantaranya adalah sebagai pigmen [2]. Kegunaan pigmen besi oksida diantaranya sebagai zat pewarna pada plastik, semen dan material konstruksi [3]. Keunggulan dari pigmen besi oksida adalah hiding power yang baik, anti korosi, ketahanan pada suhu tinggi, warna yang stabil dan tidak beracun [4]. Kualitas pigmen besi oksida dipengaruhi oleh beberapa faktor yaitu ukuran partikel pigmen, struktur dan bentuk partikel pigmen [5], metode sintesis dan kondisi sintesis seperti kecepatan pengadukan [6].

Salah satu pigmen besi oksida yang banyak dikonsumsi di Indonesia adalah pigmen geothit [7]. Geothit memiliki rentang warna berdasarkan analisis warna menggunakan color reader yaitu nilai kecerahan $\left(L^{*}\right) 51-71$, nilai corak warna $\left(\mathrm{H}^{\circ}\right)$ 72-84 [8]. Sintesis pigmen yang baik adalah pada ukuran nanopartikel dengan ukuran $<100 \mathrm{~nm}$ memiliki keuntungan sifat tinting strength yang bagus, transparansi yang bagus dan luas permukaan yang besar, distribusi ukuran partikel yang merata menyebabkan penyebaran dan penyerapan warna yang dihasilkan akan maksimal [9]. Sintesis pigmen geothit berhasil dilakukan menggunakan metode presipitasi [10]. Proses sintesis pigmen dapat menggunakan bahan pengendap antara lain hidroksida, karbonat, sulfat dan oksalat [11].

Menurut penelitian Glibert dkk. [12], sintesis pigmen geothit dengan menggunakan metode presipitasi dipengaruhi oleh kecepatan pengadukan. Pengadukan dengan kecepatan $430 \mathrm{rpm}$ menghasilkan geothit dengan ukuran 50-60 nm, sedangkan pada kecepatan $1200 \mathrm{rpm}$ menghasilkan geothit dengan ukuran 2-14 nm. Penelitian ini akan menjelaskan pengaruh kecepatan pengadukan $(550,650,750,850 \mathrm{rpm})$ terhadap sintesis geothit dari limbah bubut besi. Karakaterisasi hasil sintesis meliputi warna pigmen menggunakan color reader, panjang gelombang maksimum menggunakan UV-Vis, ukuran kristal, struktur dan komposisi geothit menggunakan instrumen XRD (X-Ray Diffractometry) dan SEM-EDX (Scanning Electron Microscope/Energy Dispersive X-Ray) yang menunjukkan kualitas pigmen yang dihasilkan.

\section{Bahan dan Metode}

\subsection{Bahan}

Limbah bubut besi didapatkan dari industri kerajinan besi di Malang. Reagen yang digunakan adalah $\mathrm{HNO}_{3} 65 \%$ (Merck), aqua demineralisasi, $\mathrm{NaHCO}_{3}$ (Merck), dan $\mathrm{NaOH}$ (Sigma-Aldrich).

\subsection{Prekursor Ferri}

Pembuatan prekursor dilakukan dengan mencampurkan $10 \mathrm{~g}$ limbah bubut besi dengan $100 \mathrm{~mL} \mathrm{HNO}{ }_{3}$ dan didiamkan selama $3 \times 24$ jam. Pemanasan dilakukan pada tahap selanjutnya dengan suhu $100^{\circ} \mathrm{C}$ hingga terbentuk padatan.

\subsection{Sintesis Geothit}

Prekursor ditambahkan $250 \mathrm{~mL}$ aqua demineralisasi selanjutnya ditambahkan $25 \mathrm{~mL} \mathrm{NaHCO} 30,5 \mathrm{M}$ dan diatur pada $\mathrm{pH} 6$ dengan penambahan $\mathrm{NaOH}$. Campuran dipanaskan pada suhu $70^{\circ} \mathrm{C}$ selama 1 jam dan diaduk dengan variasi kecepatan 550, 650, 750 dan $850 \mathrm{rpm}$. Sintesis dilakukan dengan pengulangan 3 kali. Hasil sintesis didinginkan pada suhu kamar selama 24 jam. Hasil sintesis didekantasi, selanjutnya disaring dengan menggunakan corong buchner dan pompa vakum. Pengeringan dilakukan pada suhu kamar hingga kering, lalu dihaluskan dengan menggunakan mortar agate hingga terbentuk serbuk halus.

\section{Hasil dan Pembahasan}

\subsection{Karakterisasi Kolorimeter}

Metode analisis yang digunakan adalah CIE-Lab. Pigmen geothit yang dihasilkan berwarna mulai dari kuning sampai oranye (Gambar 1). Semakin besar kecepatan pengadukan maka nilai $L^{*}$ akan semakin kecil (Gambar 2), sedangkan semakin besar kecepatan pengadukan maka warna kuning semakin gelap dan mengarah ke warna merah ( $a^{*}$ ) (Gambar 3). Kecepatan pengadukan yang semakin tinggi menyebabkan kinetika reaksi semakin besar sehingga tumbukan antar partikel semakin sering terjadi [12]. 


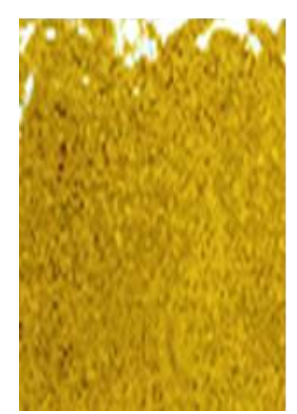

$550 \mathrm{rpm}$

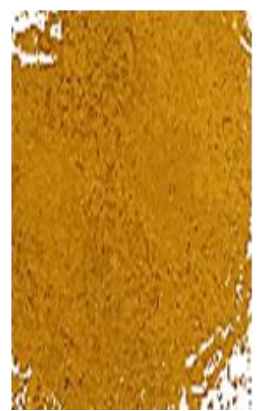

$650 \mathrm{rpm}$

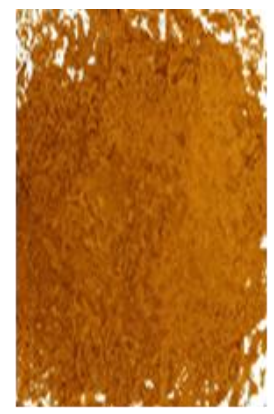

$750 \mathrm{rpm}$

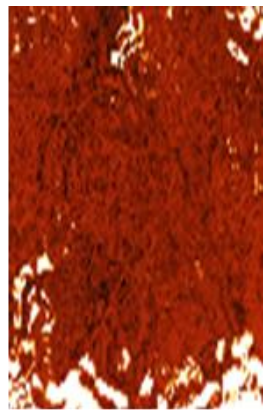

$850 \mathrm{rpm}$

Gambar 1. Warna pigmen geothit pada variasi kecepatan pengadukan.

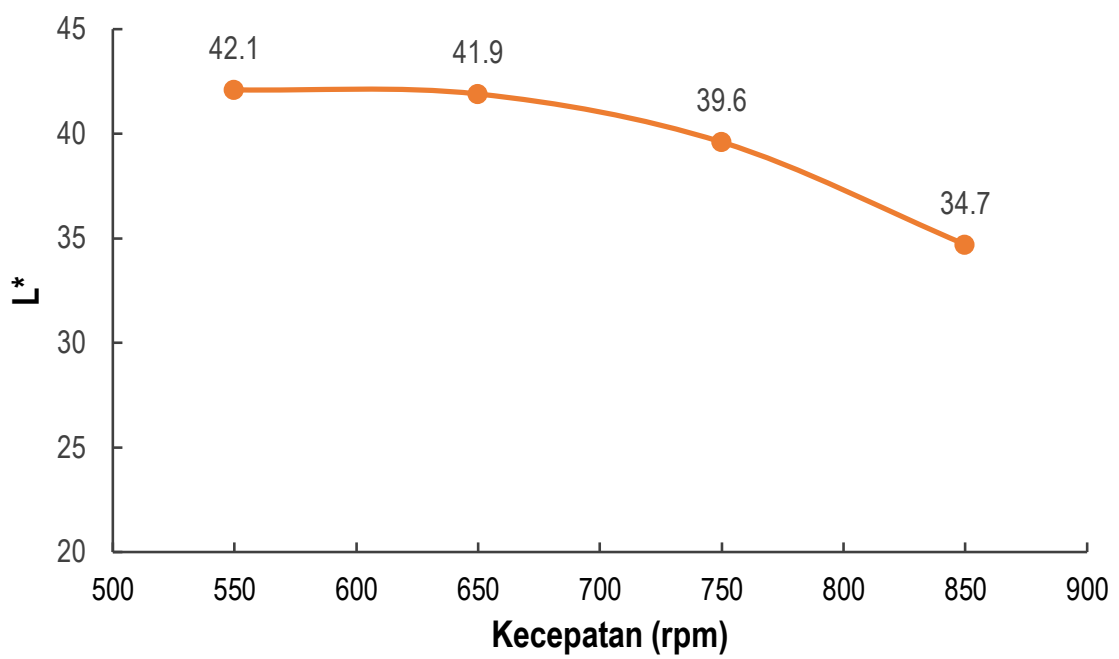

Gambar 2. Nilai Lightness (L*) pada berbagai kecepatan pengadukan.

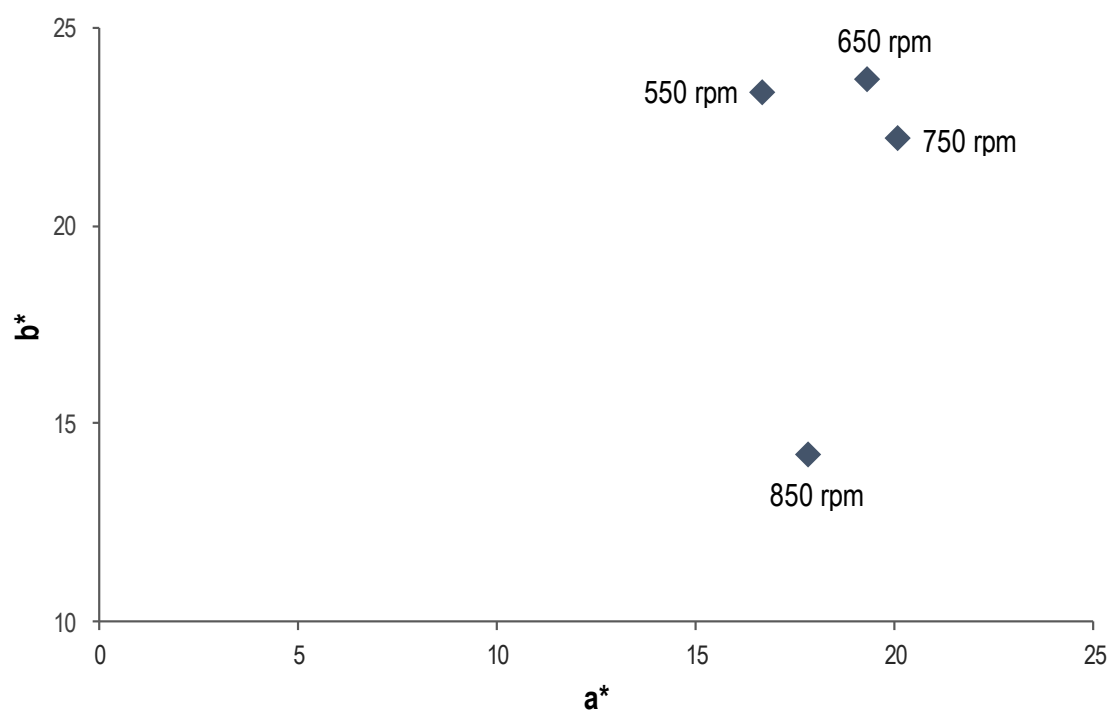

Gambar 3. Hubungan antara $a^{*}$ dan $b^{*}$ pada berbagai kecepatan pengadukan.

\subsection{Karakterisasi Spektroskopi Ultraviolet}

Pigmen geothit memiliki panjang gelombang pada 600-624 nm. Hal tersebut menunjukkan bahwa geothit termasuk ke dalam panjang gelombang sinar tampak yang berwarna oranye hingga kemerahan. Semakin besar kecepatan pengadukan maka warna cenderung gelap. Hal ini dipertegas dengan semakin besarnya panjang gelombang. Semakin besar panjang gelombangnya maka nilai Hue $\left(\mathrm{H}^{\circ}\right)$ semakin menurun. Hal tersebut menunjukkan bahwa semakin besar 
kecepatan pengadukan maka warna yang dihasilkan akan semakin gelap sehingga panjang gelombangnya semakin besar atau bergeser menuju ke warna merah (Gambar 4).

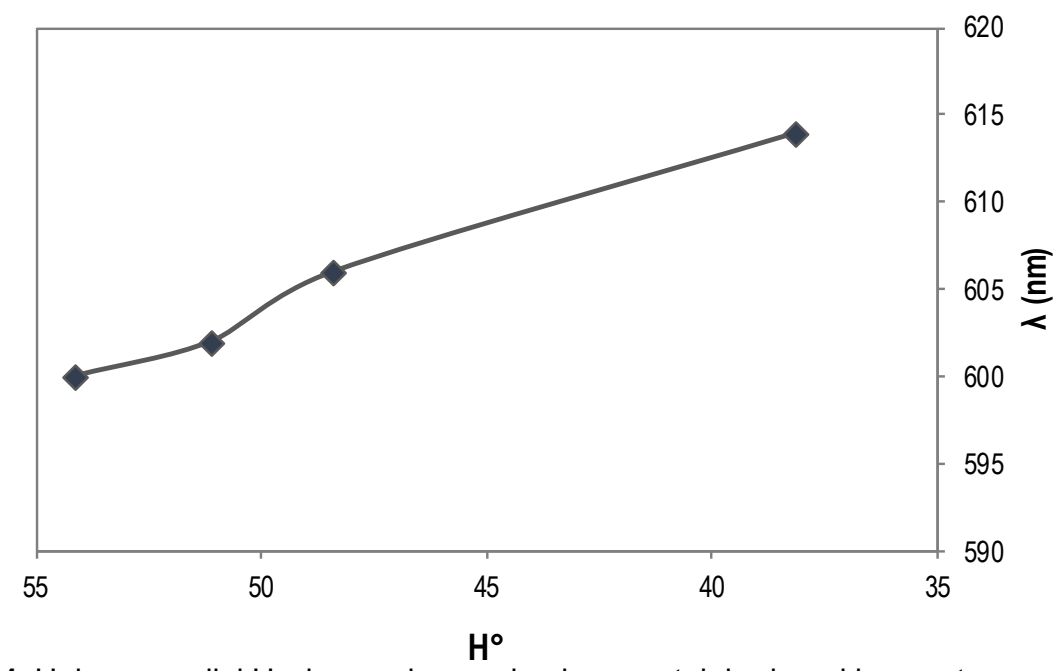

Gambar 4. Hubungan nilai $\mathrm{H}^{\circ}$ dan panjang gelombang untuk berbagai kecepatan pengadukan.

\subsection{Karakterisasi X-Ray Difraksi}

Pigmen hasil sintesis menunjukkan fasa geothit dengan struktur kristal ortorombik dan grup ruang Pnma sesuai ICSD (159958). Pola difraksi pada Gambar 5 dari pigmen yang dihasilkan muncul semua puncak sesuai dengan standar geothit, tetapi pada kecepatan pengadukan $850 \mathrm{rpm}$ pada $2 \theta(53,10)$ tidak muncul. Hal ini dimungkinkan pada kecepatan pengadukan tersebut, pigmen yang dihasilkan mulai bertransformasi menuju ke fasa lain pada oksida besi. Hal ini diperkuat dengan nilai warna $\left(a^{*}, b^{*}\right)$ yang dihasilkan cenderung mengarah ke warna merah.

Berdasarkan ukuran kristal pada Tabel 1 yang dihitung dengan persamaan Debye Schrerrer pada kecepatan pengadukan $850 \mathrm{rpm}$ didapatkan pigmen geothit dengan ukuran kristal terkecil. Penurunan ukuran kristal terjadi seiring dengan adanya penurunan kecerahan warna dan derajat kekuningan pada pigmen. Berdasarkan penelitian yang dilakukan Cornell [8], adanya hubungan antara ukuran partikel dengan kecerahan pigmen yaitu semakin kecil ukuran kristal geothit maka warna pigmen yang dihasilkan akan berkurang kecerahan warnanya. Hal ini sesuai dengan penelitian ditunjukkan dengan adanya penurunan nilai $L^{*}$ dan $b^{*}$ pada tiap penurunan ukuran kristal.

Tabel 1. Ukuran Kristal Geothit pada Variasi Kecepatan Pengadukan

\begin{tabular}{ccccc}
\hline \multirow{2}{*}{$\boldsymbol{\theta} \theta$} & \multicolumn{4}{c}{ Ukuran Kristal (nm) } \\
\cline { 2 - 5 } & $\mathbf{G . 5 5 0 ~ r p m}$ & $\mathbf{G . 6 5 0 ~ r p m}$ & $\mathbf{G . 7 5 0 ~ r p m}$ & $\mathbf{G . 8 5 0 ~ r p m}$ \\
\hline 21,12 & 63,24 & 40,92 & 24,92 & 17,61 \\
36,55 & 25,06 & 41,74 & 50,21 & 28,87 \\
\hline
\end{tabular}

\subsection{Karakterisasi SEM-EDX}

Pigmen geothit memiliki morfologi yang beragam sebagaimana Gambar 6. Pada perbesaran 2000x terlihat jelas bahwa morfologi tidak seragam karena dimungkinkan terdapat tingkat aglomerasi yang tinggi. Komposisi unsur-unsur pada pigmen geothit dijelaskan pada Tabel 2. Pengotor yang terdapat pada pigmen geothit yaitu natrium dan karbon yang dimungkinkan dari agen pengendap $\mathrm{NaHCO}_{3}$ dan bahan asal prekursor.

Tabel 2. Komposisi Unsur-Unsur pada Pigmen Geothit

\begin{tabular}{lc}
\hline \multicolumn{1}{c}{ Unsur } & Total (\%) \\
\hline Fe (besi) & 55,34 \\
$\mathrm{O}$ (oksigen) & 24,75 \\
$\mathrm{C}$ (karbon) & 18,86 \\
$\mathrm{Na}$ (natrium) & 01,04 \\
\hline
\end{tabular}




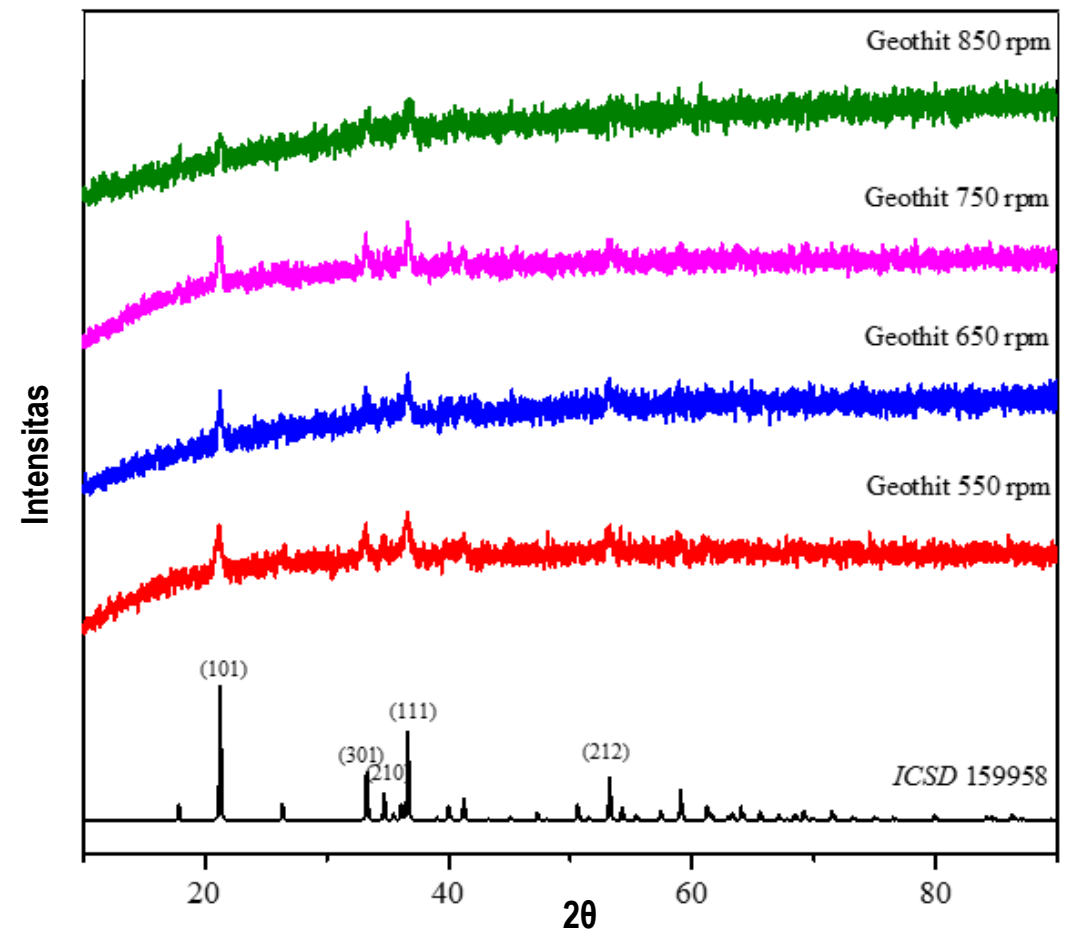

Gambar 5. Pola difraksi sinar-X senyawa geothit ( $\mathrm{a}-\mathrm{FeOOH}$ ) pada variasi kecepatan pengadukan.

(a)

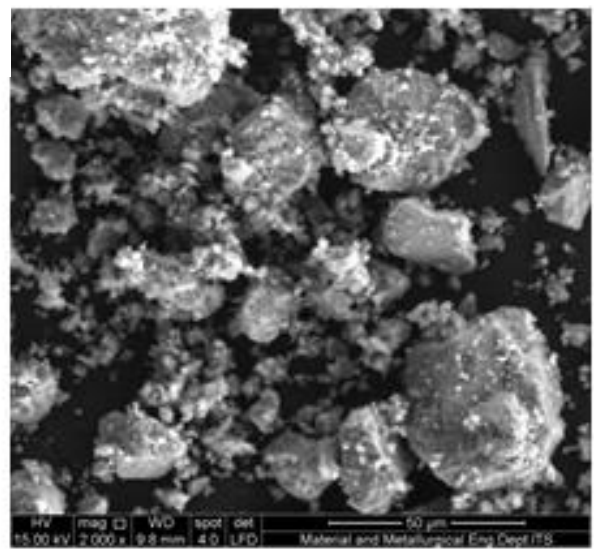

(c)

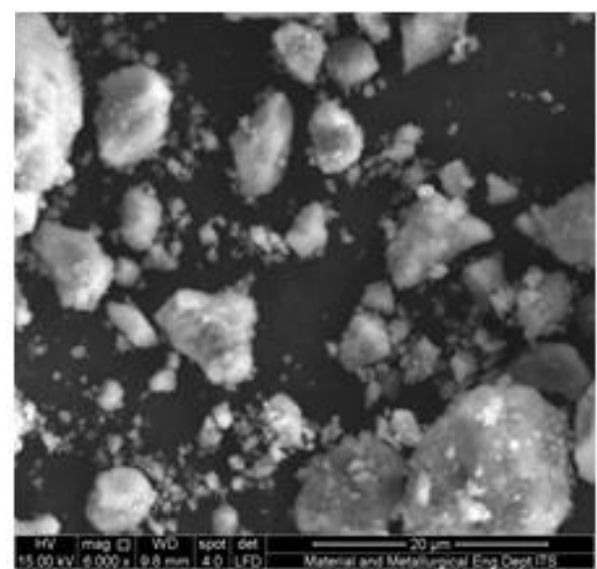

(b)

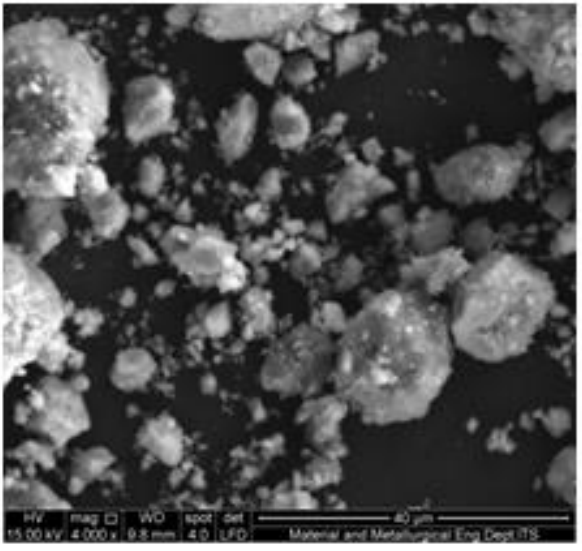

(d)

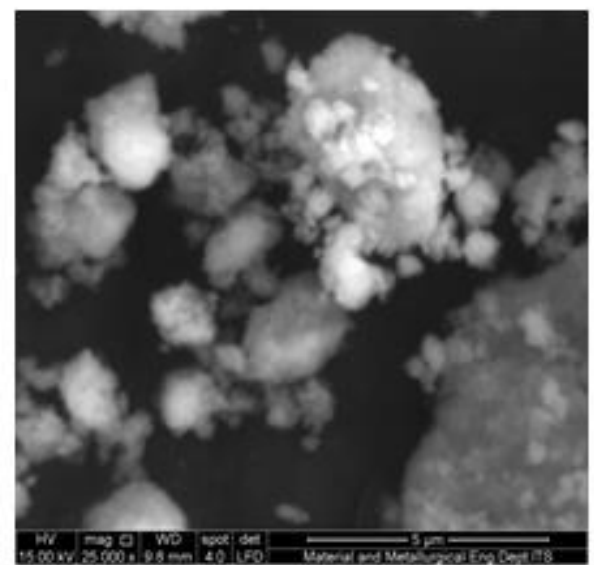

Gambar 6. Morfologi geothit kecepatan 750 rpm dengan perbesaran (a) 2000x, (b) 4000x, (c) 6000x, dan (d) 25000x. 


\section{Kesimpulan}

Pigmen hasil sintesis berfasa geothit dengan kristalinitas yang tinggi. Warna pigmen yang dihasilkan adalah kuning sampai oranye. Semakin besar kecepatan pengadukan maka warna pigmen yang dihasilkan akan semakin gelap yaitu kuning menjadi semakin merah, derajat kristalinitas dan ukuran kristal semakin menurun. Morfologi pigmen geothit beragam disebabkan adanya aglomerasi dan terdapat pengotor berupa natrium dan karbon.

\section{Daftar Pustaka}

[1] L. M. Khoiroh, "Pengaruh pH dan Suhu Kalsinasi terhadap Sintesis Pigmen Hematit $\left(\alpha-\mathrm{Fe}_{2} \mathrm{O}_{3}\right)$ dengan Metode Termal Transformasi FeOOH," Tesis, Universitas Brawijaya, Malang, 2013.

[2] S. R. Prim, M. V. Folgueras, M. A. de Lima, \& D. Hotza, "Synthesis and Characterization of Hematite Pigment Obtained from a Steel Waste Industry," Journal of Hazardous Materials, vol. 192, no. 3, pp. 1307-1313, 2011.

[3] M. A. Sørensen, F. Ingerslev, K. Bom, C. Lassen, F. Christensen, \& M. Warming, Survey of Products with Nanosized Pigments. Copenhagen: The Danish Environment Protection Agency, 2015.

[4] G. Buxbaum, Industrial Inorganic Pigments. New York: WILEY-VCH, 1998.

[5] M. A. Legodi \& D. de Waal, "The Preparation of Magnetite, Goethite, Hematite and Maghemite of Pigment Quality from Mill Scale Iron Waste," Dye and Pigments, vol. 74, no. 1, pp. 161-168, 2007.

[6] A. J. M. Tahuran, S. Parvin, A. Ahmeda, \& A. M. S. Alamb, "Studies on Black Iron Oxide Pigment. Part I : Effect of Preparation Parameter on Physical and Optical Properties of Ferrosoferric Oxide," Bangladesh Journal of Scientific and Industrial Research, vol. 43, no. 2, pp. 183-196, 2008.

[7] R. Will \& A. Kishi, CEH Marketing Research Report Pigments. USA: Chemical Economics Handbook, 2001.

[8] R. M. Cornell \& U. Schwertmann, The Iron Oxides: Structure, Properties, Reactions, Occurences and Uses. New York: Wiley-VCH Verlag GmbH \& Co., 2003.

[9] M. Mohapatra \& S. Anand, "Synthesis and Applications of Nano-Structured Iron Oxides/Hydroxides - Review," International Journal of Engineering, Science and Technology, vol. 2, no. 8, pp. 127-146, 2010.

[10] T. P. Rahman, A. Sukarto, N. T. Rochman, \& A. Manaf, "Sintesis Pigmen Besi Oksida Berbahan Baku Limbah Industri Baja (Mill Scale)," Jurnal Fisika, vol. 3, no. 1, pp. 86-89, 2013.

[11] B. R. Fernandez, "Sintesis Nanopartikel," Makalah, Universitas Andalas, Padang, 2011.

[12] F. Gilbert, P. Refait, F. Leveque, C. Remazeilles, \& E. Conforto, "Synthesis of Goethite from $\mathrm{Fe}(\mathrm{OH})_{2}$ Precipitates: Influence of Fe(II) Concentration and Stirring Speed," Journal of Physics and Chemistry of Solids, vol. 69, no. 8, pp. 2124-2130, 2008. 